\title{
Stabilizing organic photocathodes by low-temperature atomic layer deposition of $\mathrm{TiO}_{2} \uparrow$
}

\author{
Ludmilla Steier, $¥ *$ a Sebastiano Bellani, $\ddagger^{\mathrm{b}}$ Hansel Comas Rojas, $\ddagger^{\mathrm{b}}$ Linfeng Pan, ${ }^{\mathrm{a}}$ Mikko Laitinen, ${ }^{\mathrm{c}}$ \\ Timo Sajavaara, ${ }^{\mathrm{c}}$ Michael Grätzel, ${ }^{\mathrm{a}}$ Maria Rosa Antognazza, ${ }^{\mathrm{b}}$ Matthew T. Mayer $\ddagger^{* a}$
}

\begin{abstract}
Organic semiconductor light absorbers are receiving attention for their potential application in photoelectrochemical (PEC) cells for renewable fuels generation. Key to their advancement is precise control of the interfaces between charge-selective contacts, absorber layers, and electrocatalysts, while maintaining compatibility with an aqueous electrolyte environment. Here we demonstrate a new process for low-temperature atomic layer deposition (ALD) of $\mathrm{TiO}_{2}$ onto a $\mathrm{P3HT}$ :PCBM polymer blend surface for stable high-performance organic PEC photocathodes. This ALD $\mathrm{TiO}_{2}$ layer provides three key functions: 1 ) formation of an electronselective contact to the polymer to enable photovoltage and photocurrent generation, 2) a robust interface for conducting charge between the photoabsorber and electrocatalyst layers, and 3) a pinhole-free barrier to water penetration, preventing corrosion of the underlying materials. The resulting device based on the architecture Cul/P3HT:PCBM/ $/ \mathrm{TiO}_{2} / \mathrm{RuO}_{\mathrm{x}}$ showed excellent performance and stability during PEC hydrogen-evolution. More broadly, the achievement of ALD film formation on a polymer surface opens doors in the field of functional organic-inorganic electronic interfaces.
\end{abstract}

\section{Introduction}

Photoelectrochemical (PEC) water splitting is an attractive approach for the direct conversion of sunlight into chemical energy, yet the search continues for suitable absorber materials meeting the strict demands of bandgap energy, photon conversion efficiency, and stability. ${ }^{1}$ In broadening the exploration of materials beyond the inorganic semiconductors

\footnotetext{
a. Institute of Chemical Sciences and Engineering, Ecole polytechnique fédérale de Lausanne, Station 6, 1015 Lausanne, Switzerland.

b. Center for Nano Science and Technology @PoliMi, Istituto Italiano di Tecnologia, via Pascoli 70/3, 20133 Milano, Italy

c. Dept. of Physics, P.O. Box 35, 40014 University of Jyvaskyla, Finland

*Corresponding authors: I.steier@imperial.ac.uk, m.mayer@helmholtz-berlin.de

† Electronic supplementary information (ESI) available. See DOI: 10.1039/c7ee...

₹ Present affiliations: L.S.: Department of Chemistry, Imperial College London, London SW7 2AZ, UK; S.B.: Graphene Labs, Istituto Italiano di Tecnologia, via Morego 30, 16163 Genova, Italy; H.C.R.: Higher Institute for Applied Sciences and Technologies (INSTEC), Salvador Allende y Luaces, 6163, La Habana, Cuba; M.T.M.: Helmholtz-Zentrum-Berlin für Materialien und Energie, 14109 Berlin, Germany
}

\section{Broader context}

Protective thin films grown by atomic layer deposition have enabled the use of a wide variety of water-unstable light absorber materials in photoelectrochemical water splitting devices. Until now, these have been limited to inorganic absorber materials such as silicon, compound semiconductors, or other metal oxides. Organic semiconductors are receiving attention in photoelectrochemical applications, although water stability remains a challenge. We developed a low-temperature atomic layer deposition procedure to successfully form compact $\mathrm{TiO}_{2}$ films onto polymer absorber layers, creating an interface which affords corrosion protection as well as efficient charge extraction to enable efficient operation as a water splitting photocathode.

most widely studied, organic polymer-based photoabsorbers are emerging as an interesting class of materials for this application due to their solution processability, tunable energy levels, and intriguing interactions with water. ${ }^{2-5}$ Photocathodes based on donor-acceptor bulk heterojunction $(\mathrm{BHJ})$ designs have already achieved competitive efficiencies in terms of both photocurrent and photovoltage. ${ }^{6-10}$ Extended stability remains a challenge, largely due to the water-sensitive nature of many materials traditionally used in organic photovoltaic devices. ${ }^{11,12}$ Judicious selection of materials and morphologies has led to recent advancements in this area. ${ }^{13-15}$

Due to the energetic demands of water electrolysis, it is crucial that PEC devices generate the requisite photovoltages proportional to their band gaps. A key requirement toward maximizing $\mathrm{BHJ}$ device photovoltage is the use of electron- and hole-selective contacts sandwiching the absorber layer and enabling separation of photogenerated electron-hole pairs (Figure 1a). ${ }^{16}$ of the best known hole-selective layers (PEDOT:PSS, $\mathrm{MoO}_{3}, \mathrm{Cul}$, LiF), many are prone to detrimental side-reactions when contacted by water, thus requiring passivation. On the electron-selective side, $\mathrm{TiO}_{2}$ has a conduction band minimum close to that of PCBM, and furthermore is stable in water and capable of efficiently extracting electrons and conducting them to the surface catalyst for the water reduction reaction. $6,7,13$ Buried junction 

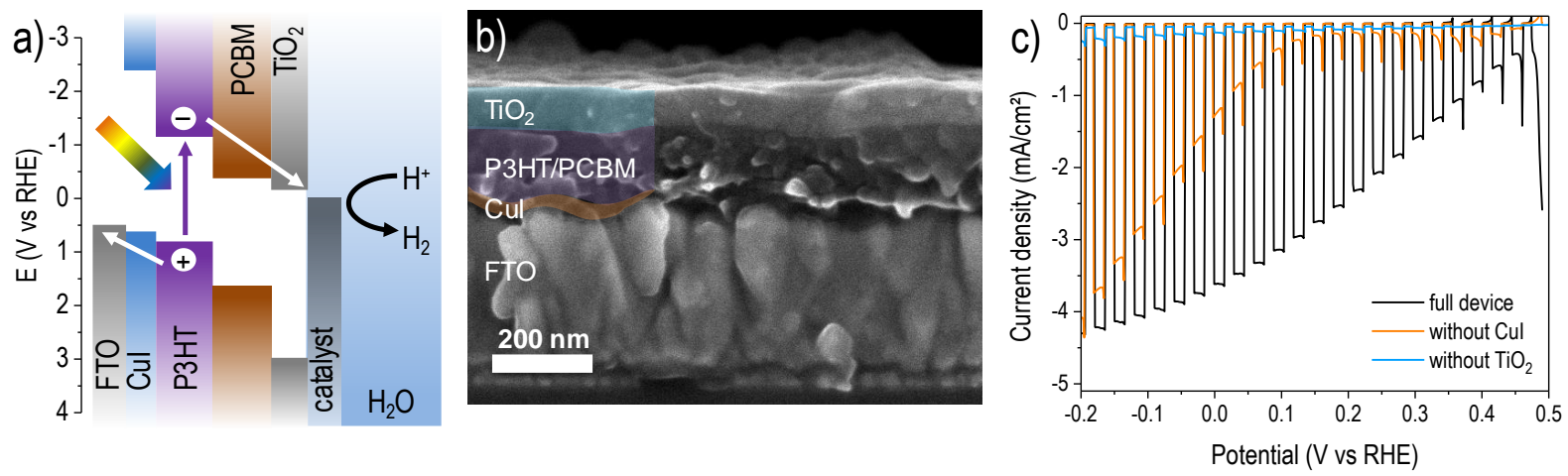

Figure 1. An organic bulk heterojunction photocathode with $\mathrm{ALD}-\mathrm{TiO}_{2}$ surface layer. (a) Energetics schematic showing relative band gaps and band edge positions of the device layers (layer thicknesses not to scale). (b) SEM cross-section image of a device after deposition of $75 \mathrm{~nm} \mathrm{ALD} \mathrm{TiO}_{2}$ on the surface. (c) Photoelectrochemical response of a photocathode device ( $\mathrm{FTO} / \mathrm{Cul} / \mathrm{P} 3 \mathrm{HT}: \mathrm{PCBM} / \mathrm{TiO}_{2}(75 \mathrm{~nm}) / \mathrm{RuO}_{\mathrm{x}}$ ) in $\mathrm{pH} 5$ electrolyte under chopped illumination (scan rate $-10 \mathrm{mV} / \mathrm{s}$ ). Photocurrent transients near 0.5 $\checkmark$ vs $\mathrm{RHE}$ result from capacitive charging of the $\mathrm{RuO}_{x}$ catalyst. ${ }^{24}$ Also shown for comparison are the responses of devices constructed without either $\mathrm{Cul}$ or $\mathrm{TiO}_{2}$ layers.

type photocathodes incorporating hole-selective substrates and electron-selective overlayers have achieved promising efficiencies, but performance degradation due to corrosion of active layers or catalyst delamination continues to pose a challenge.

$\mathrm{TiO}_{2}$ protective overlayers have been demonstrated successfully on a variety of corrosion-sensitive photocathode materials. ${ }^{17-20}$ Corrosion protection demands the $\mathrm{TiO}_{2}$ film to be conformal and pinhole-free - traits which are difficult to achieve using solution or physical vapor based deposition methods. Atomic layer deposition (ALD) is a technique capable of growing continuous, conformal metal oxide films with nanometer-scale thickness control over large deposition areas, achieved by the alternating exposure of vapor-phase metal-organic and oxidant precursors. $^{21}$ The method is most commonly used in the fabrication of inorganic semiconductor devices for microelectronic applications wherein the substrate surfaces are metals or metal oxides. Less explored is ALD onto organic substrates such as polymers. In fact, polymers may decompose at temperatures typically used in thermal ALD processes and polymer oxidation may occur during oxidant exposure. Thus far, the main applications of ALD onto polymers included surface modification, encapsulation, and templating, ${ }^{21,22}$ while very few studies have reported functioning organic-inorganic electronic interfaces via ALD. ${ }^{23}$

Despite these challenges, we sought to develop an ALD process for the formation of thin and continuous $\mathrm{TiO}_{2}$ films to serve as electron-extracting protective layers. By controlling the deposition temperature to avoid polymer degradation, using tetrakis(dimethylamido)titanium (TDMAT) as a reactive $\mathrm{Ti}$ precursor, and employing water as a mild oxidant, we achieved low-temperature $\left(80^{\circ} \mathrm{C}\right) \mathrm{ALD}$ of $\mathrm{TiO}_{2}$ onto $\mathrm{P} 3 \mathrm{HT}$ : $\mathrm{PCBM}$ organic blend surfaces, enabling the construction of efficient and stable organic photocathodes for photo-driven water reduction to hydrogen.

\section{Results \& discussion}

In our previous works, state-of-the-art ALD $\mathrm{TiO}_{2}$ overlayers for protection of corrosion-susceptible photocathodes (such as $\mathrm{Cu}_{2} \mathrm{O}$ ) were deposited using the precursors TDMAT and
$\mathrm{H}_{2} \mathrm{O} / \mathrm{H}_{2} \mathrm{O}_{2}(1: 1)$ at a deposition temperature of $150^{\circ} \mathrm{C} .{ }^{24,25}$ When using this deposition condition for $\mathrm{TiO}_{2}$ film growth onto the P3HT:PCBM blend surface, the devices showed little photoresponse, producing photocurrents below $10 \mu \mathrm{A} \mathrm{cm}{ }^{-2}$. We therefore sought milder deposition conditions with the aim of preserving polymer photoactivity while maintaining reasonable deposition times. Room temperature ALD of $\mathrm{TiO}_{2}$ was recently reported using TDMAT and ozone; ${ }^{26}$ however, ozone is too strong an oxidizer for deposition on photoactive polymers. ${ }^{27} \mathrm{We}$ discovered a compromise of deposition conditions, adopting a low-temperature process at $80{ }^{\circ} \mathrm{C}$ using $\mathrm{H}_{2} \mathrm{O}$ alone as oxidant (see the Methods section for complete details). TDMAT is reported to be highly reactive with $\mathrm{H}_{2} \mathrm{O}$ at temperatures as low as $50{ }^{\circ} \mathrm{C},{ }^{28}$ and hence ideal for the low-temperature ALD coating of our polymer bend. We found that compact $\mathrm{TiO}_{2}$ films formed atop the P3HT:PCBM blend under these conditions. The growth rate measured on silicon was approximately $0.9 \AA$ per cycle during the $80^{\circ} \mathrm{C}$ deposition, in good agreement with the trend reported by Xie et al. ${ }^{28}$

To evaluate the compositional purity, we examined $\mathrm{TiO}_{2}$ films grown on silicon by time-of-flight elastic recoil detection analysis (TOF-ERDA) and found relatively high hydrogen concentrations as well as higher oxygen content than expected for $\mathrm{TiO}_{2}$ ( $\mathrm{Ti}: \mathrm{O}=1: 2.2$ instead of 1:2) (Table 1 and Figure $\mathbf{S 1}$ in the $\mathrm{SI})$. This suggests that our low-temperature ALD films may contain a small amount of unreacted $\mathrm{OH}$ groups. Also the carbon and nitrogen concentrations in the film were considerable ( $\sim 2 \%$ and $\sim 1 \%$, respectively) indicating that residual ligands from the TDMAT precursor might be incorporated into the $\mathrm{TiO}_{2}$ film. Similar amounts of carbon have been reported previously for $\mathrm{TiO}_{2}$ films grown by lowtemperature ALD. ${ }^{29}$ The $\mathrm{OH}$ groups and residual ligands are likely to inhibit the formation of crystalline $\mathrm{TiO}_{2}$, thus resulting in amorphous $\mathrm{TiO}_{2}$ films at temperatures below the crystallization temperature of $\mathrm{TiO}_{2}\left(165^{\circ} \mathrm{C}\right) .^{30}$ 

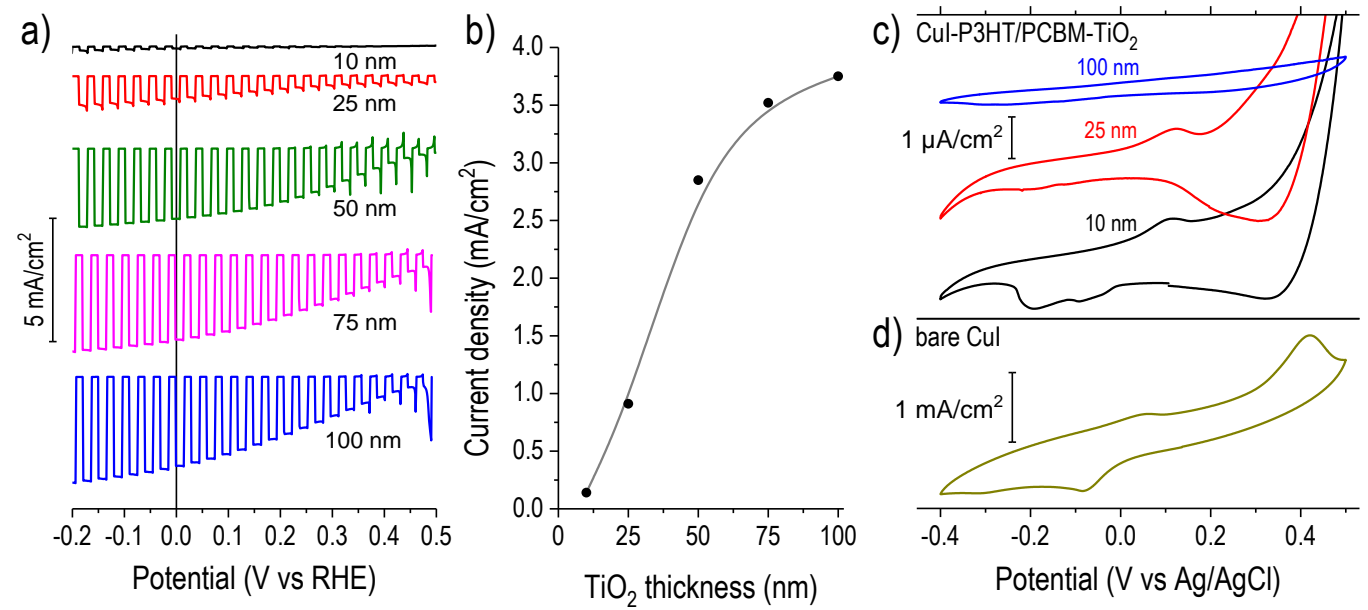

Figure 2. Electrochemical behaviors for devices with varied $\mathrm{TiO}_{2}$ overlayer thicknesses. (a) Chopped light linear sweep voltammetry (scan rate -10 $\mathrm{mV} / \mathrm{s}$ ) of $\mathrm{Cul} / \mathrm{P} 3 \mathrm{HT}: \mathrm{PCBM} / \mathrm{TiO}_{2} / \mathrm{RuO}_{x}$ photocathodes with $\mathrm{TiO}_{2}$ thicknesses labelled, and (b) a plot of the trend in photocurrent densities at $0 \mathrm{~V}$ vs $\mathrm{RHE}$ as a function of $\mathrm{TiO}_{2}$ thickness. (c) Cyclic voltammetry (CV) measurements in dark for three representative catalyst-free devices $\left(\mathrm{Cul} / \mathrm{P} 3 \mathrm{HT}: \mathrm{PCBM} / \mathrm{TiO}_{2}\right)$ of varied $\mathrm{TiO}_{2}$ thicknesses as labeled (scale bar $\left.=1 \mu \mathrm{A} / \mathrm{cm}^{2}\right)$ compared to (d) the dark $\mathrm{CV}$ of a bare Cul sample $(\mathrm{scale}$ bar $=$ $\left.1 \mathrm{~mA} / \mathrm{cm}^{2}\right)$. Scan rates $=100 \mathrm{mV} / \mathrm{s}$, electrolyte $\mathrm{pH}=5$

Table 1. Elemental composition (atom \%) extracted from TOF-ERDA (Supplementary Figure $\mathbf{S 1 b}$, pink region) of a representative $90 \mathrm{~nm}$ thick $\mathrm{TiO}_{2}$ film deposited on a Si wafer.

\begin{tabular}{|c|c|}
\hline Element & Atom $\%$ \\
\hline $\mathrm{Ti}$ & $27 \pm 2$ \\
\hline $\mathrm{O}$ & $60 \pm 2$ \\
\hline $\mathrm{H}$ & $10 \pm 1.5$ \\
\hline $\mathrm{C}$ & $2.2 \pm 0.4$ \\
\hline $\mathrm{N}$ & $1.2 \pm 0.3$ \\
\hline
\end{tabular}

Using this mild ALD $\mathrm{TiO}_{2}$ process, it was possible to form continuous films atop the polymer blend without negatively affecting its photoactivity, confirmed by fabricating complete photocathode devices. For this study we focused on a state-ofthe-art organic photocathode composed of a solutionprocessed copper (I) iodide (Cul) hole-selective layer (deposited on a fluorine doped tin oxide substrate, FTO) and a P3HT:PCBM bulk heterojunction blend active layer. ${ }^{7}$ We then modified it with our low-temperature $\mathrm{ALD} \mathrm{TiO}_{2}$ as well as a photoelectrodeposited $\mathrm{RuO}_{x}$ hydrogen evolution catalyst. ${ }^{24}$ The device energy schematic diagram is shown in Figure 1a, and a representative scanning electron micrograph (SEM, Figure $\mathbf{1 b}$ ) reveals the nature of the ALD $\mathrm{TiO}_{2}$ coated photocathode. Intimate contact between the light absorbing blend and the charge-selective layers is apparent. As shown in Figure 1c, the full Cul/P3HT:PCBM/ $\mathrm{TiO}_{2} / \mathrm{RuO}_{\mathrm{x}}$ device performed well as a water reducing photocathode in $\mathrm{pH} 5$ electrolyte, with a photovoltage of $c a .0 .5 \mathrm{~V}$ and photocurrent density reaching around $-4 \mathrm{~mA} \mathrm{~cm} \mathrm{~cm}^{-2}$ under one-sun illumination intensity. Our photovoltage closely approaches the open circuit potential of a state-of-the-art P3HT:PCBM OPV device suggesting that 1) electrons are successfully extracted through the amorphous $\mathrm{TiO}_{2}$ layer and 2) the device is a buried junction type photocathode. ${ }^{31,32}$ The photoelectrochemical performances of analogous devices lacking either the Cul substrate layer or $\mathrm{TiO}_{2}$ overlayer are also shown, revealing the importance of both the hole- and electron-selective contacts in enabling efficient charge separation and photovoltage generation in the bulk heterojunction device.

We then investigated more closely the role of $A L D \mathrm{TiO}_{2}$ as passivation and electron-selective layer. The photoelectrochemical response for devices with 10 to $100 \mathrm{~nm}$ thick $\mathrm{TiO}_{2}$ overlayers are shown in Figure 2a. For devices without $\mathrm{TiO}_{2}$, the photocurrents were negligible. ${ }^{7}$ Interestingly, with increasing $\mathrm{TiO}_{2}$ thickness the photocurrent magnitude concomitantly increased until stabilizing for overlayers of 75$100 \mathrm{~nm}$, as summarized in Figure 2b. The photocurrents under constant bias (Figure S2) confirm this trend. $\mathrm{TiO}_{2}$ has a wide band gap and is not expected to generate noticeable photocurrent itself in this configuration. In the following, we seek to understand this correlation between photocurrent magnitude and ALD $\mathrm{TiO}_{2}$ thickness.

To evaluate the electrochemical role of the $\mathrm{TiO}_{2}$ overlayer, we performed cyclic voltammetry (CV) in the dark on catalystfree devices (Figure 2c). Copper (I) compounds are usually susceptible to reduction-oxidation processes when in contact with water, and this was confirmed by observation of large peaks in the CV of bare Cul on FTO (Figure 2d). Bare films of $\mathrm{P} 3 \mathrm{HT}$ or PCBM did not exhibit significant redox peaks in this potential range (Figure S3). On the P3HT:PCBM devices with thin $\mathrm{TiO}_{2}$ overlayers ( 10 and $25 \mathrm{~nm}$ ) the peaks were suppressed by three orders of magnitude (note the $\mu \mathrm{A} / \mathrm{cm}^{2}$ scale bar) but were still evident. The persistence of these peaks points to a possible failure pathway where the Cul can be electrochemically reduced or oxidized during photocathode operation when in contact with water. This is in agreement with the rapid photocurrent degradation for devices with thin $\mathrm{TiO}_{2}$ shown in Figure S2 and the eventual delamination of the polymer film shown in Figure S4. Conversely, for a P3HT:PCBM device coated with $100 \mathrm{~nm} \mathrm{TiO}$, we observed the complete suppression of the reduction-oxidation peaks attributable to Cul.

The role of $\mathrm{TiO}_{2}$ can be further understood by examining the catalyst deposition process. Figure $\mathbf{S} 5$ shows the measured device potential during galvanostatic cathodic photoelectrochemical deposition of $\mathrm{RuO}_{\times}$on samples of varied $\mathrm{TiO}_{2}$ 
thickness. When the illumination was briefly chopped off, devices with thicker $\mathrm{TiO}_{2}$ showed large negative shifts in potential, signifying the large bias necessary to drive the reduction of $\mathrm{RuO}_{4}^{2-}$ at $-36 \mathrm{\mu A} / \mathrm{cm}^{2}$ through a rectifying photocathode in dark, similar to the behavior observed on $\mathrm{TiO}_{2-}$ protected $\mathrm{Cu}_{2} \mathrm{O}$ devices. ${ }^{24}$ On the contrary, the 10 and $25 \mathrm{~nm}$ $\mathrm{TiO}_{2}$ devices showed the reverse trend, shifting slightly positive in dark. This behavior results from the "shunt" pathway between the Cul/P3HT:PCBM layers and water through the $\mathrm{TiO}_{2}$, which therefore fails to build a rectifying, photovoltageproducing junction. In this situation, much of the applied current goes to reducing $\mathrm{Cul}$ rather than driving the $\mathrm{RuO}_{x}$ deposition. This situation is depicted schematically in Figure S6. Hence, the trend seen in Figure $2 \mathrm{a}$ likely originates from 1 ) photovoltage losses due to the lack of a rectifying $\mathrm{TiO}_{2}$ contact and 2) lower catalyst loading on devices with thinner $\mathrm{TiO}_{2}$ films due to the side reaction of Cul reduction.

The thinner $\mathrm{TiO}_{2}$ overlayers provide inadequate corrosion protection and fail to form an effective electron-selective junction to the polymer blend. Conversely, previous results from our group showed that an $\mathrm{ALD} \mathrm{TiO}_{2}$ layer of about $11 \mathrm{~nm}$ could be sufficient to inhibit the corrosion processes of underlying materials $\left(\mathrm{Cu}_{2} \mathrm{O}\right.$ and $\left.\mathrm{ZnO}\right)$ across this potential window. ${ }^{33}$ We hypothesized that this greater susceptibility to corrosion could be caused by an irregular ALD growth mechanism of $\mathrm{TiO}_{2}$ films onto the polymer blend wherein they might not initiate uniformly but instead proceed by nucleation and island growth, requiring greater film thicknesses to form a continuous protective layer. During ALD film growth, the initial nucleation step is important for the formation of continuous and pinhole-free films. ${ }^{21}$ Previous reports of oxide ALD $\left(\mathrm{Al}_{2} \mathrm{O}_{3}\right.$ and $\mathrm{ZnO}$ ) onto polymers showed that ALD precursors can diffuse into polymer films, becoming kinetically trapped and then reacting with the $\mathrm{H}_{2} \mathrm{O}$ pulse to form embedded particles, rather than forming compact films on the surface. ${ }^{23,34-36}$ In those studies, the metal oxide particles were clearly visible via backscattered electron (BSE) imaging of the film cross-section. To examine this possibility, we also performed BSE imaging of our devices (Figure S7). In contrast to the reports described above, we observed only compact films on the polymer surface with no evidence of particle formation within the film. The fact that TDMAT is significantly bulkier than the precursors used for $\mathrm{ZnO}$ and $\mathrm{Al}_{2} \mathrm{O}_{3}$ (diethylzinc and trimethylaluminum, respectively) might explain its suppressed diffusion and the absence of $\mathrm{TiO}_{2}$ nucleation within the polymer. Nevertheless, a Volmer-Weber type growth of islands on the polymer blend surface, which coalesce into a compact film above a critical thickness, is reasonable to assume. A high-resolution SEM crosssection image of a device with a thick ALD $\mathrm{TiO}_{2}$ film (Figure S8) reveals apparent domains on the order of 30-70 nm in diameter. Hence, thin $\mathrm{TiO}_{2}$ films $(<70 \mathrm{~nm})$ might be permeable to water and only become impermeable once the grains grow together. This is in agreement with the thickness-dependent observations of device performance and stability (Figure 2), although more detailed study of $\mathrm{TiO}_{2}$ film nucleation on the polymer blend film is warranted to better understand the unique growth mechanism of ALD $\mathrm{TiO}_{2}$ on the polymer blend surface.
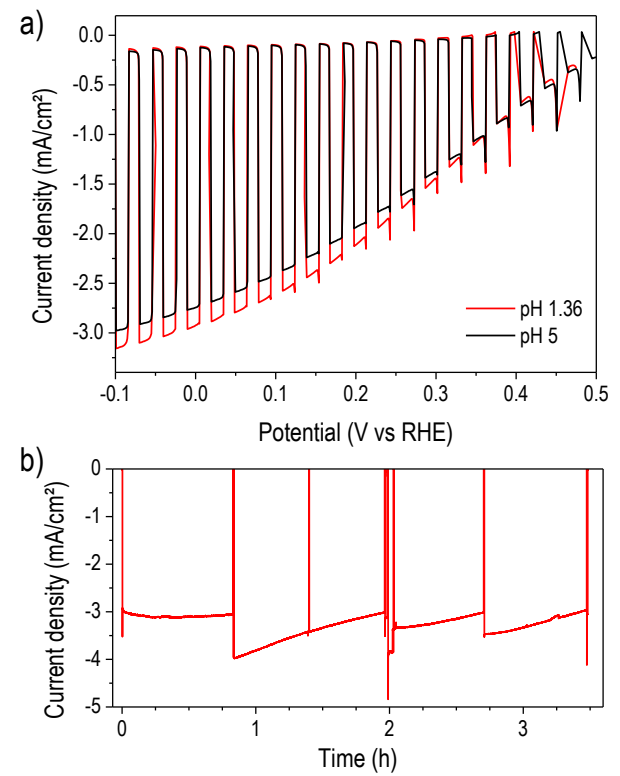

Figure 3. (a) Comparison of photoelectrochemical performance under chopped illumination of a typical device with $75 \mathrm{~nm} \mathrm{TiO}_{2}$ in $\mathrm{pH} 5$ and pH 1.36 electrolytes. (b) Extended testing in $\mathrm{pH} 1.36$ electrolyte under illumination (simulated one-sun) and constant bias ( $0 \mathrm{~V}$ vs RHE). Occasionally, the light was blocked to check the dark current magnitude, at which time a pipette was used to dislodge bubbles accumulated on the sample surface, causing recovery of the photocurrent magnitude. Between 2.1 and $2.7 \mathrm{~h}$, a KG3 filter was applied to the illumination beam to observe the effect of an IR-free spectrum.

For a practical water reduction photocathode, operation in acidic electrolyte is more effective than at near-neutral $\mathrm{pH},{ }^{37}$ so we next examined device performance in $\mathrm{pH} 1.36$ electrolyte. As shown in Figure $3 a$, the photocathodes exhibited similar performance in $\mathrm{pH} 5$ and $\mathrm{pH} 1.36$ solutions. The slight photocurrent increase in acidic solution likely results from the improved mass transport of protons, preventing their depletion and the formation of a $\mathrm{pH}$ gradient. Extended testing in $\mathrm{pH} 1.36$ under illumination and bias at $0 \mathrm{~V}$ vs RHE revealed excellent stability of the $\mathrm{TiO}_{2}$-protected device for over three hours of operation (Figure 3b). The low-temperature ALD $\mathrm{TiO}_{2}$ therefore provided robust corrosion protection in both acidic and nearneutral $\mathrm{pH}$ as well as a stable interface with the surface electrocatalyst. While several recent studies demonstrated P3HT:PCBM-based photoelectrodes protected by $\mathrm{TiO}_{2}$ synthesized by various methods including pulsed laser deposition ${ }^{6,7,13}$ and solution-based methods, ${ }^{14,38-40}$ the present result stands out for simultaneously achieving both high performance and excellent stability.

\section{Conclusions}

In summary, we demonstrated a novel low-temperature ALD method for depositing compact $\mathrm{TiO}_{2}$ onto photoactive organic semiconductor blends successfully forming a functional electronic interface within a state-of-the-art photocathode for photoelectrochemical water splitting. These ALD $\mathrm{TiO}_{2}$ coated organic photocathodes could achieve operating stability over several hours. We attribute three important functions to the ALD $\mathrm{TiO}_{2}$ layer in the resulting devices: 1 ) formation of an electron-selective contact to the P3HT:PCBM bulk 
heterojunction to enable photovoltage generation, 2) protection against corrosion of the Cul underlayer (during both catalyst electrodeposition and hydrogen evolution) and 3) charge mediation from the absorber layer to the surface electrocatalyst for robust photoelectrochemical hydrogen evolution. This result broadens the protective layer approach to organic and temperature-sensitive photoabsorber materials, achieving excellent stability and paving the way forward for new efficient, stable, and low-cost organic photocathodes. Beyond the stable high-performance photoelectrodes shown here, this ALD approach could find utility in forming transparent top contacts to organic photovoltaic cells or in other hybrid organic-inorganic (inverted) semiconductor devices.

\section{Methods}

Photocathode devices were prepared using the same materials and procedures described in a previous report, ${ }^{7}$ with the exception of the $\mathrm{TiO}_{2}$ and catalyst layer deposition. In summary, copper iodide was deposited onto F-doped $\mathrm{SnO}_{2}$ (FTO) glass substrates via spin coating using a solution of $10 \mathrm{~g} \mathrm{~L}$ $1 \mathrm{Cul}$ in acetonitrile. Then P3HT (regio-regular poly(3hexylthiophene-2,5-diyl) and PCBM ([6,6]-phenyl C61 butyric acid methyl ester) were dissolved in chlorobenzene and the solution was spin coated onto the FTO/Cul substrates to form the active layer blend. Samples were exposed to ambient air during shipment (usually 2-3 days) and were subsequently stored in Argon until proceeding to the $\mathrm{TiO}_{2}$ deposition stage.

Atomic layer deposition (ALD) of $\mathrm{TiO}_{2}$ was carried out using a home-built ALD reactor. ${ }^{41}$ Importantly, to avoid excessive heating of the polymer blend films under ambient air exposure, the chamber was cooled to below $40{ }^{\circ} \mathrm{C}$ before inserting and removing the samples. The substrates were heated only after evacuating the chamber to $\sim 0.3$ mbar under inert $\mathrm{N}_{2}$ (Carbagas, 99.999\% pure) flow. Since the P3HT:PCBM films need to crystallize for higher photoactivity, prior to the deposition we subjected the samples to a controlled temperature program as follows: 1) Ramping from $40{ }^{\circ} \mathrm{C}$ to $80^{\circ} \mathrm{C}$ over $180 \mathrm{~s}, 2$ ) ramping to $135^{\circ} \mathrm{C}$ over $180 \mathrm{~s}, 3$ ) equilibrating at $140{ }^{\circ} \mathrm{C}$ for $180 \mathrm{~s}$ and 4) cooling down to $80^{\circ} \mathrm{C}$ to start ALD of $\mathrm{TiO}_{2}$ (within $10 \mathrm{~min}$ ). $\mathrm{TiO}_{2}$ film deposition was then carried out at $80{ }^{\circ} \mathrm{C}$ in exposure mode with pulse, exposure and purge times of $0.1 \mathrm{~s} / 15 \mathrm{~s} / 70 \mathrm{~s}$ for $\mathrm{H}_{2} \mathrm{O}$ (held at room temperature) and $0.1 \mathrm{~s} / 15 \mathrm{~s} / 25 \mathrm{~s}$ for tetrakis(dimethylamino) titanium, (TDMAT, heated at $75^{\circ} \mathrm{C}$ ) with $5 \mathrm{sccm} \mathrm{N}$ flow. Deposition at a chamber temperature of $80^{\circ} \mathrm{C}$ resulted in a growth rate of $0.9 \AA \mathrm{Acycle}^{-1}$ on a Si wafer as measured by ellipsometry (Sopra GES $5 E$ ) and confirmed by SEM on the polymer blends.

Following ALD $\mathrm{TiO}_{2}$ deposition, the sample edges were passivated by epoxy (Loctite $9461 \mathrm{Hysol}$ ), which also defined the sample area exposed to illumination. Surface areas of about 0.5 $\mathrm{cm}^{2}$ were employed. $\mathrm{RuO}_{\mathrm{x}}$ electrocatalyst was deposited by photo-electrodeposition, wherein the device was immersed into a $1.3 \mathrm{mM}$ solution of $\mathrm{KRuO}_{4}$ in water, illuminated by a solar simulator at one-sun intensity, and subjected to $900 \mathrm{~s}$ of galvanostatic current density of $-36 \mu \mathrm{A} \mathrm{cm} \mathrm{cm}^{-2}$.

During photoelectrochemical testing, the illumination source was a solar simulator (Newport LCS-100 with Xenon lamp and integrated AM 1.5G filter, class A spectral match) calibrated to achieve one-sun intensity using a Si diode cell with known spectral responsivity. The standard electrolyte was an aqueous solution of $\mathrm{Na}_{2} \mathrm{SO}_{4}(0.5 \mathrm{M})$ and $\mathrm{NaH}_{2} \mathrm{PO}_{4}(0.1 \mathrm{M})$ adjusted to $\mathrm{pH} 5$ by addition of $\mathrm{NaOH}(1 \mathrm{M})$. The acidic electrolyte was $0.1 \mathrm{M} \mathrm{Na}_{2} \mathrm{SO}_{4}$ adjusted to $\mathrm{pH} 1.36$ by addition of $0.1 \mathrm{M} \mathrm{H}_{2} \mathrm{SO}_{4}$. A three-electrode configuration was used for all measurements, with the photocathode as working electrode, an $\mathrm{Ag} / \mathrm{AgCl}$ (sat. $\mathrm{KCl}$ ) reference electrode, and a Pt wire counter electrode. A potentiostat (BioLogic SP-200) measured the device response.

Scanning electron micrographs were obtained on a Zeiss Merlin instrument equipped with an in-lens secondary electron detector, a backscattered electron detector, and an energydispersive X-ray spectroscopy detector. Samples were physically cleaved for cross-section imaging.

TOF-ERDA measurements were carried out in a $1.7 \mathrm{MV}$ Pelletron accelerator at the Accelerator Laboratory of the University of Jyväskylä with using a $11.913 \mathrm{MeV}{ }^{63} \mathrm{Cu}^{6+}$ ion beam aligned in a $20^{\circ}$ tilt angle to the sample surface, ${ }^{42}$ and the collected data were analyzed using Potku TOF-ERDA analysis software. ${ }^{43}$

\section{Conflicts of interest}

There are no conflicts to declare.

\section{Acknowledgements}

This work was supported by the European Commission Seventh Framework Programme project PHOCS (agreement no. 309223) and Academy of Finland Center of Excellence in Nuclear and Accelerator Based Physics (ref. no. 251353). The authors thank Dr. J. Luo for experimental support on the SEM analysis.

\section{References}

1 K. Sivula and R. van de Krol, Nat. Rev. Mater., 2016, 1, 15010.

2 T. Abe, S. Tobinai, N. Taira, J. Chiba, T. Itoh and K. Nagai, J. Phys. Chem. C, 2011, 115, 7701-7705.

3 S. Bellani, D. Fazzi, P. Bruno, E. Giussani, E. V. Canesi, G. Lanzani and M. R. Antognazza, J. Phys. Chem. C, 2014, 118, 6291-6299.

4 E. Mosconi, P. Salvatori, M. I. Saba, A. Mattoni, S. Bellani, F. Bruni, B. Santiago Gonzalez, M. R. Antognazza, S. Brovelli, G. Lanzani, H. Li, J.-L. Brédas and F. De Angelis, ACS Energy Lett., 2016, 1, 454-463.

5 T. Abe, M. Ichikawa, T. Hikage, S. Kakuta and K. Nagai, Chem. Phys. Lett., 2012, 549, 77-81.

6 F. Fumagalli, S. Bellani, M. Schreier, S. Leonardi, H. C. Rojas, A. Ghadirzadeh, G. Tullii, A. Savoini, G. Marra, L. Meda, M. Grätzel, G. Lanzani, M. T. Mayer, M. R. Antognazza and F. Di Fonzo, J. Mater. Chem. A, 2016, 4, 2178-2187.

$7 \quad$ H. C. Rojas, S. Bellani, F. Fumagalli, G. Tullii, S. Leonardi, M. T. Mayer, M. Schreier, M. Grätzel, G. Lanzani, F. Di Fonzo and M. R. Antognazza, Energy Environ. Sci., 2016, 9, 37103723. 

Jousselme and V. Artero, Nanotechnology, 2016, 27, 355401. V. Artero and B. Jousselme, ACS Appl. Mater. Interfaces, 2015, 7, 16395-16403. S. Bellani, L. Najafi, A. Capasso, A. E. Del Rio Castillo, M. R. Antognazza and F. Bonaccorso, J. Mater. Chem. A, 2017, 5, 33 4384-4396. M. P. Nikiforov, J. Strzalka and S. B. Darling, Sol. Energy Mater. Sol. Cells, 2013, 110, 36-42. M. Jørgensen, K. Norrman, S. A. Gevorgyan, T. Tromholt, B. Andreasen and F. C. Krebs, Adv. Mater., 2012, 24, 580-612. A. Mezzetti, F. Fumagalli, A. Alfano, D. ladicicco, M. R Antognazza and F. di Fonzo, Faraday Discuss., 2017, 198, 433-448. Campidelli, R. Cornut and B. Jousselme, J. Mater. Chem. A, 2016, 4, 4831-4839. S.-Y. Park, M. Kim, J. Jung, J. Heo, E. M. Hong, S. M. Choi, J.Y. Lee, S. Cho, K. Hong and D. C. Lim, J. Power Sources, 2017, 341, 411-418.

E. L. Ratcliff, B. Zacher and N. R. Armstrong, J. Phys. Chem. Lett., 2011, 2, 1337-1350.

S. Hu, N. S. Lewis, J. W. Ager, J. Yang, J. R. McKone and N. C. Strandwitz, J. Phys. Chem. C, 2015, 119, 24201-24228. B. Seger, T. Pedersen, A. B. Laursen, P. C. K. Vesborg, O. Hansen and I. Chorkendorff, J. Am. Chem. Soc., 2013, 135, 1057-64.

M. Schreier, P. Gao, M. T. Mayer, J. Luo, T. Moehl, M. K. Nazeeruddin, S. D. Tilley and M. Grätzel, Energy Environ. Sci., 2015, 8, 855-861.

J. Luo, Z. Li, S. Nishiwaki, M. Schreier, M. T. Mayer, P. Cendula, Y. H. Lee, K. Fu, A. Cao, M. K. Nazeeruddin, Y. E. Romanyuk, S. Buecheler, S. D. Tilley, L. H. Wong, A. N. Tiwari and M. Grätzel, Adv. Energy Mater., 2015, 5, 1501520.

S. M. George, Chem. Rev., 2010, 110, 111-131.

H. C. Guo, E. Ye, Z. Li, M.-Y. Han and X. J. Loh, Mater. Sci. Eng. C, 2017, 70, 1182-1191.

S. Obuchovsky, I. Deckman, M. Moshonov, T. Segal Peretz, G. Ankonina, T. J. Savenije and G. L. Frey, J. Mater. Chem. C, 2014, 2, 8903-8910.

S. D. Tilley, M. Schreier, J. Azevedo, M. Stefik and M. Grätzel, Adv. Funct. Mater., 2014, 24, 303-311.

P. Dias, M. Schreier, S. D. Tilley, J. Luo, J. Azevedo, L. Andrade, D. Bi, A. Hagfeldt, A. Mendes, M. Grätzel and M. T. Mayer, Adv. Energy Mater., 2015, 5, 1501537. A. K. Bishal, C. Sukotjo and C. G. Takoudis, J. Vac. Sci. Technol. A Vacuum, Surfaces, Film., 2017, 35, 01B134. H. Hintz, H.-J. Egelhaaf, H. Peisert and T. Chassé, Polym. Degrad. Stab., 2010, 95, 818-825.

Q. Xie, Y.-L. Jiang, C. Detavernier, D. Deduytsche, R. L. Van Meirhaeghe, G.-P. Ru, B.-Z. Li and X.-P. Qu, J. Appl. Phys., 2007, 102, 83521.

M. Aghaee, P. S. Maydannik, P. Johansson, J. Kuusipalo, M. Creatore, T. Homola and D. C. Cameron, J. Vac. Sci.

Technol. A Vacuum, Surfaces, Film., 2015, 33, 41512.
J. Aarik, A. Aidla, T. Uustare and V. Sammelselg, J. Cryst. Growth, 1995, 148, 268-275.

A. G. Scheuermann and P. C. McIntyre, J. Phys. Chem. Lett., 2016, 7, 2867-2878.

A. C. Nielander, M. R. Shaner, K. M. Papadantonakis, S. a Francis and N. S. Lewis, Energy Environ. Sci., 2015, 8, 1625.

A. Paracchino, V. Laporte, K. Sivula, M. Grätzel and E. Thimsen, Nat. Mater., 2011, 10, 456-461.

C. A. Wilson, R. K. Grubbs and S. M. George, Chem. Mater., 2005, 17, 5625-5634.

S. Obuchovsky, B. Shamieh, I. Deckman, G. Ankonina and G. L. Frey, Sol. Energy Mater. Sol. Cells, 2015, 143, 280283.

S. Obuchovsky, H. Frankenstein, J. Vinokur, A. K. Hailey, Y.L. Loo and G. L. Frey, Chem. Mater., 2016, 28, 2668-2676.

J. Jin, K. Walczak, M. R. Singh, C. Karp, N. S. Lewis and C. Xiang, Energy Environ. Sci., 2014, 7, 3371-3380.

M. Haro, C. Solis, G. Molina, L. Otero, J. Bisquert, S. Gimenez and A. Guerrero, J. Phys. Chem. C, 2015, 119, 6488-6494.

M. Haro, C. Solis, V. M. Blas-Ferrando, O. Margeat, S. Ben Dhkil, C. Videlot-Ackermann, J. Ackermann, F. Di Fonzo, A. Guerrero and S. Gimenez, ChemSusChem, 2016, 9, 30623066.

H. C. Rojas, S. Bellani, E. A. Sarduy, F. Fumagalli, M. T. Mayer, M. Schreier, M. Grätzel, F. Di Fonzo and M. R. Antognazza, ACS Omega, 2017, 2, 3424-3431. L. Steier, J. Luo, M. Schreier, M. T. Mayer, T. Sajavaara and M. Grätzel, ACS Nano, 2015, 9, 11775-11783. M. Laitinen, M. Rossi, J. Julin and T. Sajavaara, Nucl. Instruments Methods Phys. Res. Sect. B Beam Interact. with Mater. Atoms, 2014, 337, 55-61.

K. Arstila, J. Julin, M. I. Laitinen, J. Aalto, T. Konu, S. Kärkkäinen, S. Rahkonen, M. Raunio, J. Itkonen, J.-P. Santanen, T. Tuovinen and T. Sajavaara, Nucl. Instruments Methods Phys. Res. Sect. B Beam Interact. with Mater. Atoms, 2014, 331, 34-41. 


\section{Supporting Information}

\section{Stabilizing organic photocathodes by low-temperature atomic layer deposition of $\mathrm{TiO}_{2}$}

Ludmilla Steier, $\ddagger^{* a}$ Sebastiano Bellani,$\ddagger^{\mathrm{b}}$ Hansel Comas Rojas, $\ddagger^{\mathrm{b}}$ Linfeng Pan, ${ }^{\mathrm{a}}$ Mikko Laitinen, ${ }^{\mathrm{c}}$ Timo Sajavaara, ${ }^{\mathrm{c}}$ Michael Grätzel, ${ }^{a}$ Maria Rosa Antognazza, ${ }^{b}$ Matthew T. Mayer $* a$

a. Institute of Chemical Sciences and Engineering, Ecole polytechnique fédérale de Lausanne, Station 6, 1015 Lausanne, Switzerland.

b. Center for Nano Science and Technology @PoliMi, Istituto Italiano di Tecnologia, via Pascoli 70/3, 20133 Milano, Italy

c. Dept. of Physics, P.O. Box 35, 40014 University of Jyvaskyla, Finland

*Corresponding authors: I.steier@imperial.ac.uk,m.mayer@helmholtz-berlin.de

\# Present affiliations: L.S.: Department of Chemistry, Imperial College London, London SW7 2AZ, UK; S.B.: Graphene Labs, Istituto Italiano di Tecnologia, via Morego

30, 16163 Genova, Italy; H.C.R.: Higher Institute for Applied Sciences and Technologies (INSTEC), Salvador Allende y Luaces, 6163, La Habana, Cuba; M.T.M.:

Helmholtz-Zentrum-Berlin für Materialien und Energie, 14109 Berlin, DE

a)

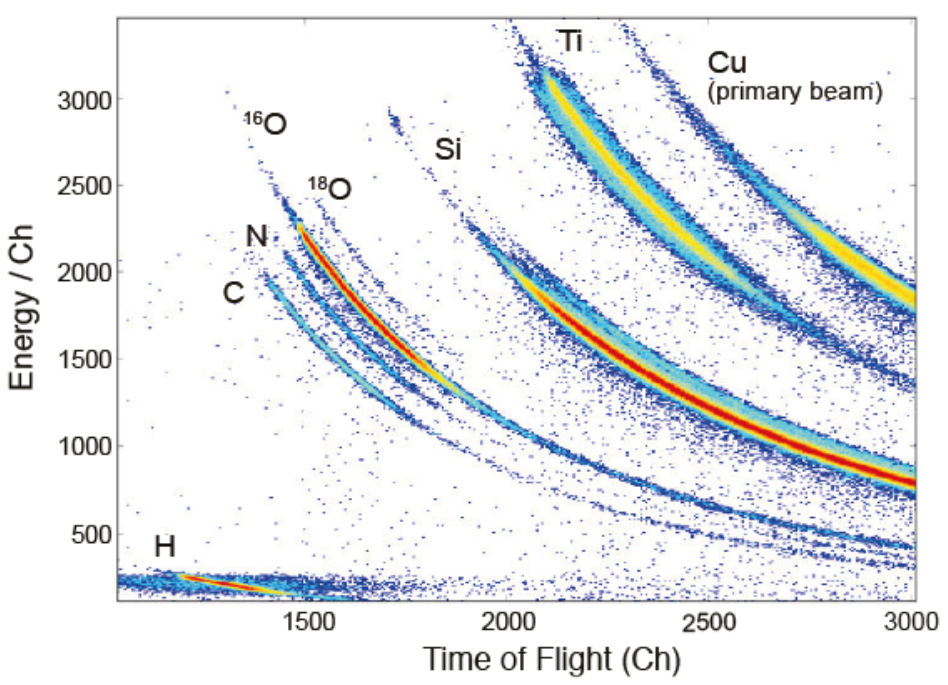

b)

c)
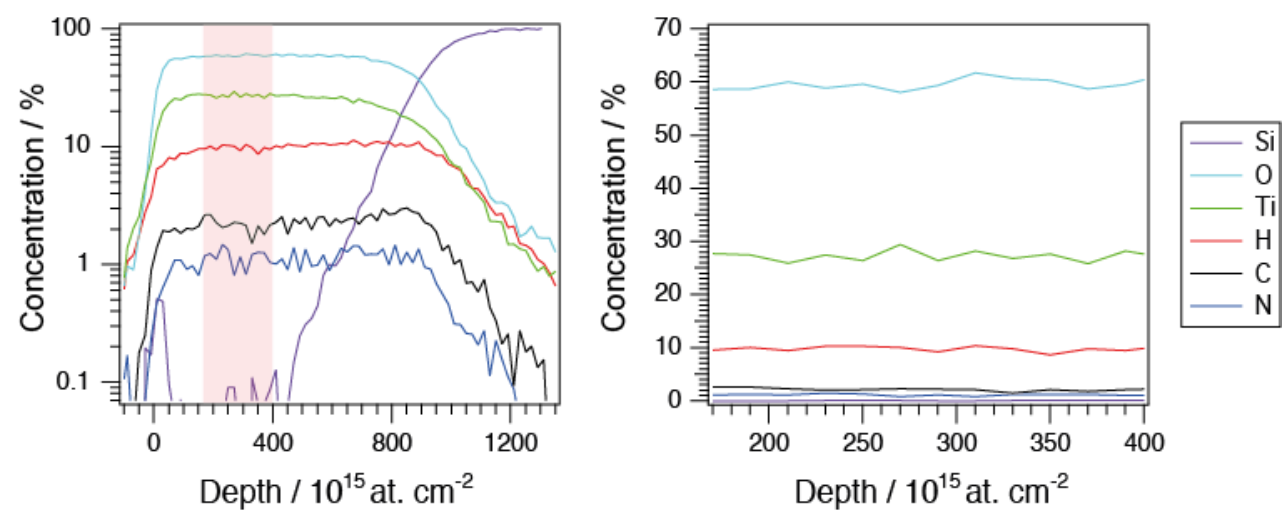

Figure S1. a) Histogram of coincident time-of-flight and energy events for $\mathrm{ALD} \mathrm{TiO}_{2}$ grown at $80^{\circ} \mathrm{C}$ with TDMAT and $\mathrm{H}_{2} \mathrm{O}$ on silicon wafers showing hydrogen, carbon, nitrogen, both isotopes of oxygen, silicon and titanium as well as copper from the primary beam for a $90 \mathrm{~nm}$ thick TiO film on Si. b) Concentration depth profiles for the $90 \mathrm{~nm}$ thick $\mathrm{TiO}_{2}$ samples from a). Values in Table 1 were averaged from the pink marked region that is presented in a linear plot in c). No elemental losses were observed during the measurements. Hydrogen, carbon and nitrogen concentrations increase slightly towards the interface. 


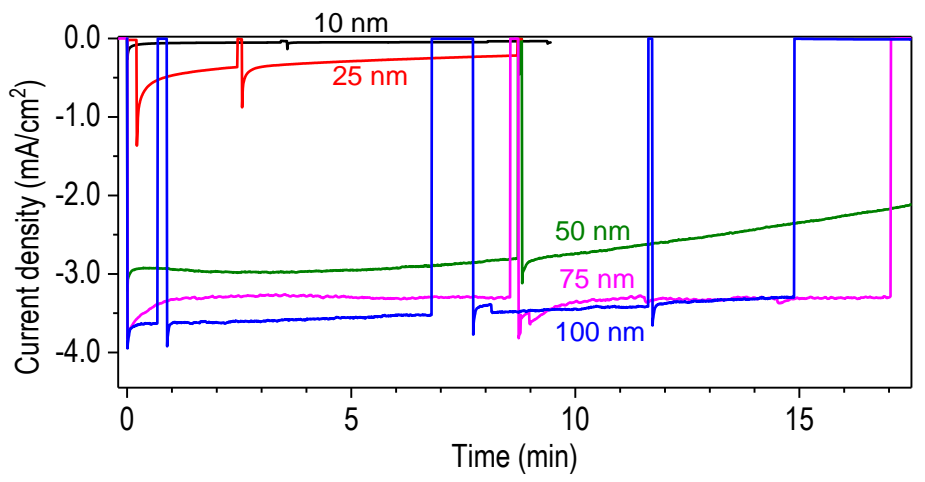

Figure S2. Constant potential ( 0 V vs RHE) measurements of $\mathrm{Cul} / \mathrm{P3} \mathrm{HT}: \mathrm{PCBM} / \mathrm{TiO}_{2} / \mathrm{RuO}_{\mathrm{x}}$ photocathodes with varied $\mathrm{ALD} \mathrm{TiO}_{2}$ thicknesses as labeled, under steady illumination that was periodically blocked to observe the current in dark. All measurements were performed in $\mathrm{pH} 5$ electrolyte under simulated one-sun illumination.
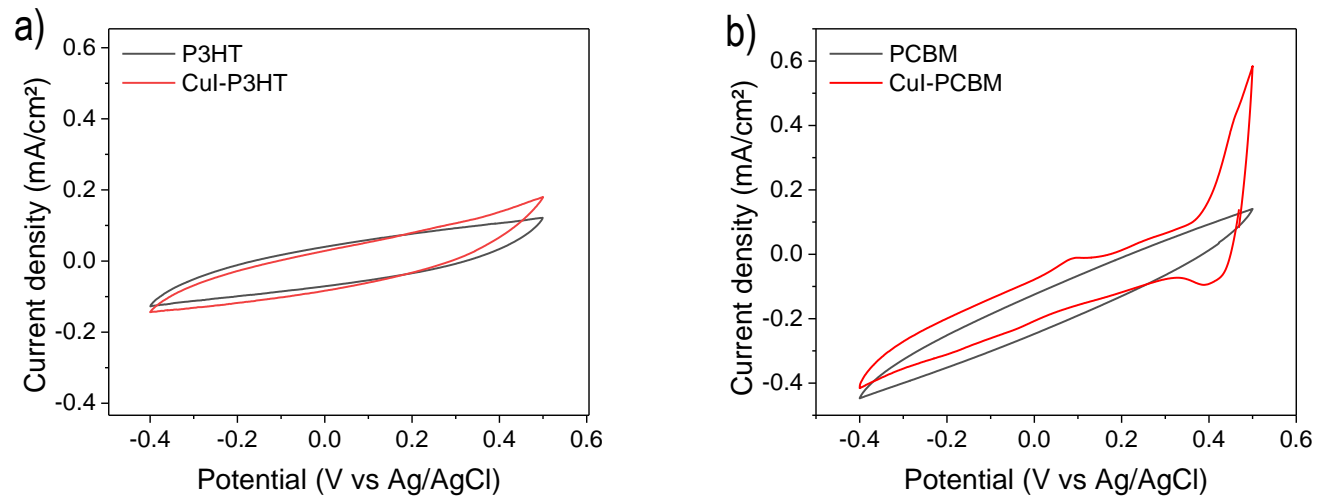

Figure S3. Cyclic voltammetry scans of films of a) P3HT and b) PCBM deposited onto bare FTO substrates (black) and onto Cul-coated FTO (red). Scan rates = $100 \mathrm{mV} / \mathrm{s}$, electrolyte $\mathrm{pH}=5$. Around 5-10 repeated scan cycles were performed for each, and the data presented here are representative behaviours observed during this period.

A

B

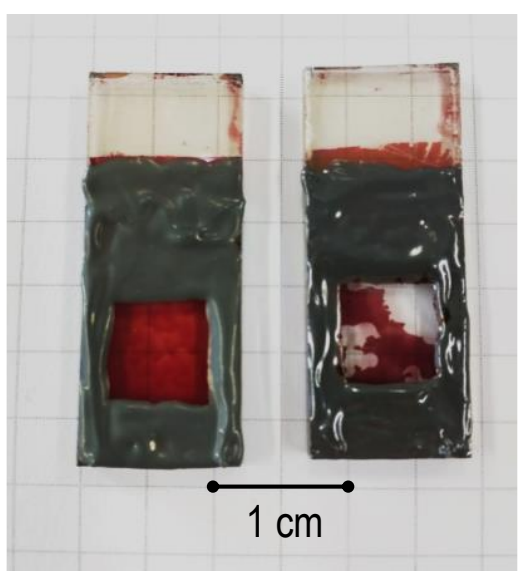

Figure S4. Photographs of photocathodes after extended testing. Devices with $75 \mathrm{~nm} \mathrm{TiO}{ }_{2}$ tested for (A) $90 \mathrm{~min}$. and (B) $300 \mathrm{~min}$. in pH 5 electrolyte at 0 V vs RHE. Sample degradation initiates at the edge of the epoxy, suggesting that the encapsulation strategy may stress the $\mathrm{TiO}_{2}$ overlayer and cause defects through which electrolyte can penetrate. The purple $\mathrm{P} 3 \mathrm{HT}$ :PCBM film gradually delaminates from the FTO surface, indicative of dissolution of the Cul underlayer. 


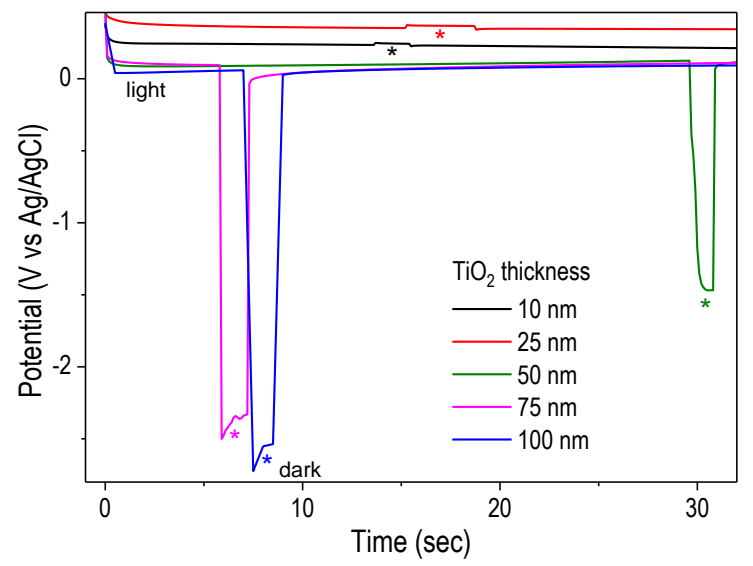

Figure S5. Potential measurement during $\mathrm{RuO}_{\mathrm{x}}$ catalyst photo-electrodeposition on devices of varied $\mathrm{TiO}_{2}$ thickness. A reducing galvanostatic current density of $-36 \mu \mathrm{A} / \mathrm{cm}^{2}$ was fixed for $900 \mathrm{~s}$ total, and simulated one-sun illumination was applied constantly except when briefly blocked during the moments labeled by asterisks $\left({ }^{*}\right)$.

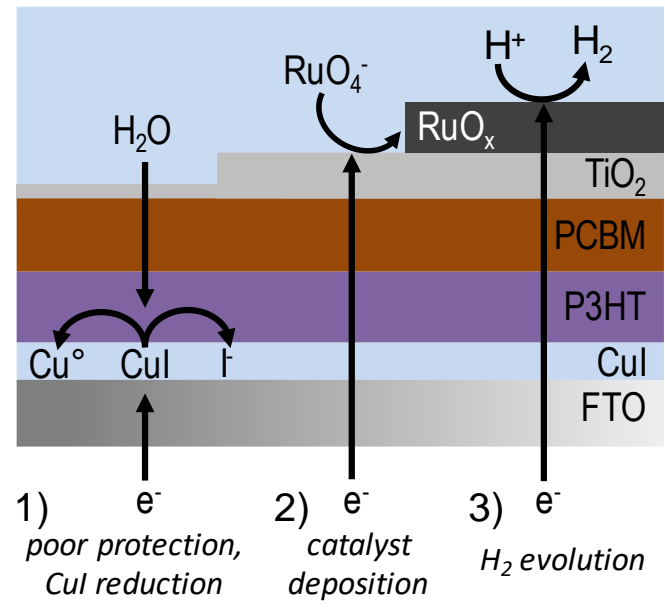

Figure S6. Schematic illustration of charge transport and transfer processes which are sensitive to $\mathrm{TiO}_{2}$ overlayer thickness. 1) When $\mathrm{TiO}_{2}$ is thin or absent, $\mathrm{H}_{2} \mathrm{O}$ can penetrate

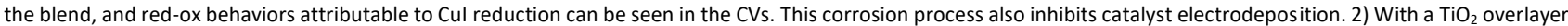
electrons are efficiently collected from the blend and transported to the surface where they drive the catalyst electrodeposition, forming a $\mathrm{RuO}_{\mathrm{x}}$ film. 3 ) The full device with catalyst drives photoelectrochemical hydrogen evolution. Note that photoexcitation of electrons in P3HT is not depicted here, and the illustration is not to scale.
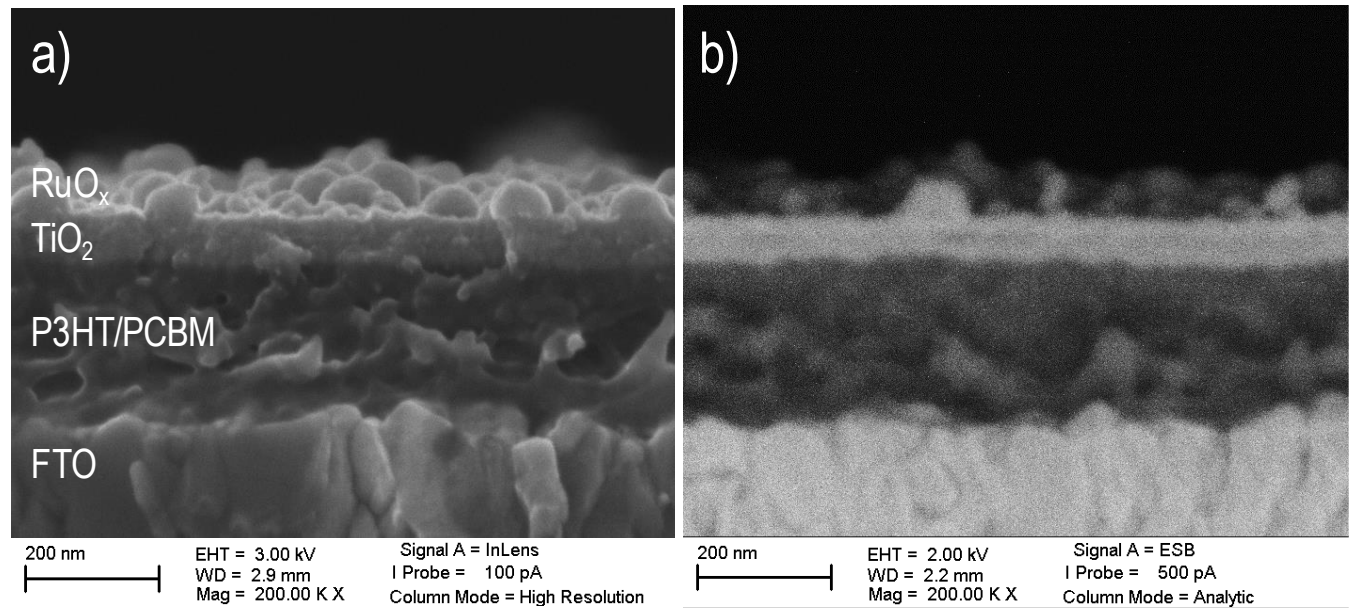

Figure S7. Scanning electron microscopy imaging of cleaved photocathode cross-sections for a Cul/P3HT:PCBM/TiO $/ \mathrm{RuO}_{x}$ device with 75 nm ALD TiO 2 . a) Secondary electron imaging. b) Electron backscatter imaging. The bright areas in the backscatter image arise from the enhanced scattering from heavy atoms such as metals ( $\mathrm{Ti}, \mathrm{Ru}$, and $\mathrm{Sn}$ ). There is no clear evidence of $\mathrm{TiO}_{2}$ penetration into the polymer film. 


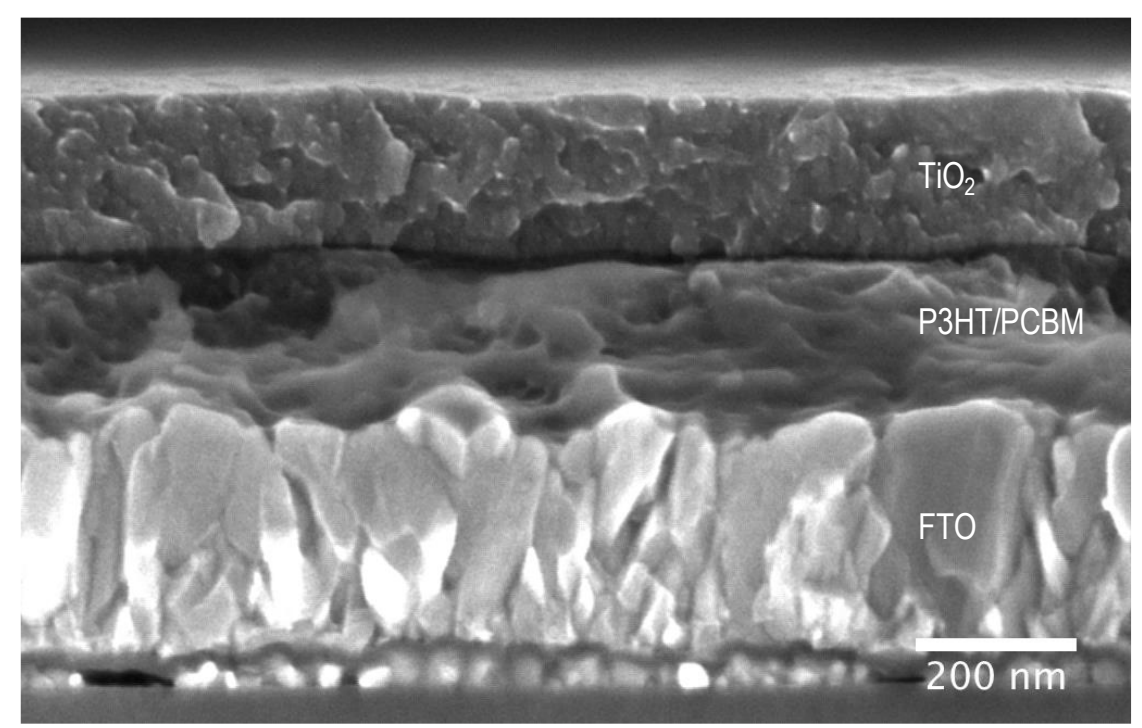

Figure 58. High-resolution SEM cross-section image of a Cul/P3HT:PCBM/TiO 2 device. 